\title{
Transformational leadership, creativity, and organizational innovation
}

\author{
Lale Gumusluoglu ${ }^{a, *}$, Arzu Ilsev ${ }^{b, 1}$ \\ ${ }^{\text {a }}$ Bilkent University, Faculty of Business Administration, Department of Management, Bilkent, Ankara, Turkey \\ ${ }^{\mathrm{b}}$ Hacettepe University, Faculty of Economics and Administrative Sciences, Department of Business Administration, Beytepe, Ankara, Turkey
}

Received 1 December 2006; received in revised form 1 June 2007; accepted 1 July 2007

\begin{abstract}
This study proposes a model of the impact of transformational leadership both on followers' creativity at the individual level and on innovation at the organizational level. The model is tested on 163 R\&D personnel and managers at 43 micro- and small-sized Turkish software development companies. The results suggest that transformational leadership has important effects on creativity at both the individual and organizational levels. At the individual level, the results of hierarchical linear modeling show that there is a positive relationship between transformational leadership and employees' creativity. In addition, transformational leadership influences employees' creativity through psychological empowerment. At the organizational level, the results of regression analysis reveal that transformational leadership positively associates with organizational innovation, which is measured with a market-oriented criterion developed specifically for developing countries and newly developing industries. The implications of the findings along with some potential practical applications are discussed.
\end{abstract}

(C) 2008 Elsevier Inc. All rights reserved.

Keywords: Transformational leadership; Creativity; Organizational innovation; Turkey

Innovation through creativity is an important factor in the success and competitive advantage of organizations (Woodman et al., 1993) as well as for a strong economy (Drucker, 1985). Today, almost all organizations face a dynamic environment characterized by rapid technological change, shortening product life cycles, and globalization. Organizations, especially technologically-driven ones, need to be more creative and innovative than before to survive, to compete, to grow, and to lead (Jung et al., 2003; Tierney et al., 1999).

The literature includes several definitions of creativity and innovation. A widely accepted definition states that creativity is the production of novel and useful ideas, and innovation is the successful implementation of creative ideas within an organization (Amabile, 1983, 1998; Amabile et al., 1996). Thus, creativity is at the individual level, while innovation is at the organizational level (Oldham and Cummings, 1996).

\footnotetext{
* Corresponding author. Tel.: +90 312290 2319; fax: +90 3122664958.

E-mail addresses: tomruk@bilkent.edu.tr (L. Gumusluoglu), ailsev@hotmail.com (A. Ilsev).

${ }^{1}$ Tel.: +90 312299 2064; fax: +90 3122992055 .
}

Interest is growing in the influence of transformational leadership on creativity and innovation. Transformational leaders raise the performance expectations of their followers (Bass, 1995) and 'seek to transform followers' personal values and selfconcepts, and move them to higher level of needs and aspirations" (Jung, 2001: 187). Researchers have studied the effects of transformational leadership on the performance of followers and organizations in the past decade (e.g., Dvir et al., 2002; Howell and Avolio, 1993; Lowe et al., 1996), but only a handful of studies have examined the effects of this type of leadership on followers' creativity. The conflicting findings as well as the experimental nature of these studies prompt the present research which primarily aims to understand the effects of transformational leadership on followers' creativity in a real setting.

The intrinsic motivation perspective dominates the creativity literature. This perspective argues that people are most creative primarily via intrinsic motivation (e.g., Amabile, 1983, 1998; Tierney et al., 1999). Amabile et al. (1996) further suggest that an individual's perception of the work environment is a key determinant of his or her creativity. According to their model, the perceived work environment influences the creative work 
carried out in organizations; that is, the psychological meaning employees attach to events in their organizations affect their motivation to generate new ideas. Previous literature has examined several psychological work environment perceptions that can influence creative work in organizations. For example, studies show perceptions of support for innovation (Scott and Bruce, 1994) and psychological empowerment (Deci et al., 1989) to be important sources of creativity.

Several studies report that transformational leaders empower their followers (e.g., Jung and Sosik, 2002) and establish an innovative climate (Jung et al., 2003). However, available research does not examine the mediating roles of empowerment and innovative climate in the relationship between transformational leadership and followers' creativity. This study proposes that employees' intrinsic motivation and perceptions of the work environment, specifically perceptions of support for innovation and empowerment, are the mechanisms underlying the effects of transformational leadership on creativity.

Along with the relationship between transformational leadership and followers' individual-level creativity and the underlying potential mediating processes, this study also investigates the relationship between transformational leadership and innovation at the organizational level. Extending the model to this level of analysis should be a significant contribution to the literature because only a handful of empirical studies have looked at the effect of transformational leadership on organizational innovation (e.g., Jung et al., 2003). More importantly, since innovation at the organizational level is the result of creative efforts and achievements in commercial organizations, gaining an understanding of the effect of this form of leadership on organizational innovation is as important as understanding its effect on employees' creativity. This study aims to examine the effects of transformational leadership on creativity at the individual level and innovation at the organizational level. Fig. 1 shows the multilevel model developed for this purpose.

According to the proposed model, transformational leadership positively relates to followers' creativity. Followers' intrinsic motivation, psychological empowerment, and perception of support for innovation mediate this effect. At the organizational level, transformational leadership positively relates to organizational innovation. Furthermore, individuallevel creativity influences innovation at the organizational level.

\section{Theoretical background and hypotheses}

\subsection{Transformational leadership and individual creativity}

Burns (1978) introduces the transformational leadership theory. Bass and Avolio (1995) further developed the theory. According to them, transformational leadership has four components; charismatic role modeling, individualized consideration, inspirational motivation, and intellectual stimulation. Using charisma, the leader inspires admiration, respect, and loyalty, and emphasizes the importance of having a collective sense of mission. By individualized consideration, the leader builds a one-to-one relationship with his or her followers, and understands and considers their differing needs, skills, and aspirations. By inspirational motivation, the leader articulates an exciting vision of the future, shows the followers how to achieve the goals, and expresses his or her belief that they can do it. By intellectual stimulation, the leader broadens and elevates the interests of his or her employees (Bass, 1990b), and stimulates followers to think about old problems in new ways (Bass, 1985).

Transformational leadership behaviors closely match the determinants of innovation and creativity at the workplace, some of which are vision, support for innovation, autonomy, encouragement, recognition, and challenge (Elkins and Keller, 2003). This leader's behaviors are likely to act as "creativityenhancing forces": individualized consideration "serves as a reward" for the followers by providing recognition and encouragement; intellectual stimulation "enhances exploratory thinking" by providing support for innovation, autonomy, and challenge; and inspirational motivation "provides encouragement into the idea generation process" by energizing followers to work towards the organization's vision (Bass and Avolio, 1995; Sosik et al., 1998: 113). The resulting intrinsic motivation felt by the followers is an important source of creativity (Tierney et al., 1999).

Moreover, since feelings of self-efficacy lead to higher creative performance (Mumford and Gustafson, 1988; Redmond et al., 1993), transformational leaders who develop their followers' selfefficacy (Bass, 1990b) can positively affect their followers' creativity. Employees with enhanced self-efficacy are more likely to be motivated to generate novel ideas and solutions. Furthermore, the emotional relationships a transformational

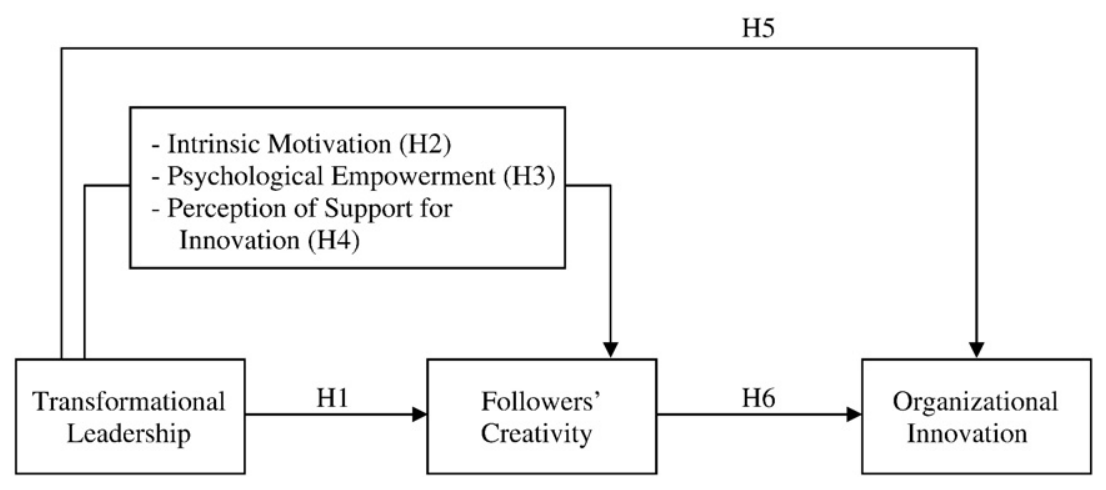

Fig. 1. The proposed model. 
leader builds with his or her followers (Bass, 1990b) might be another creativity-enhancing force as emotional attachment is likely to lead to higher levels of creativity (Hunt et al., 2004). That is, employees are more likely to respond to this leader's challenge and support for innovation by exhibiting more creativity in their tasks, given their emotional ties with their leader.

Although transformational leadership seems to be relevant in enhancing followers' creativity, only a few studies investigate this relationship empirically. With the exception of the research of Shin and Zhou (2003), these studies (Sosik et al., 1998, 1999; Jung, 2001; Kahai et al., 2003; Jaussi and Dionne, 2003), use data from the U.S., in experimental settings, and using student samples; they report inconsistent findings about this leader's effect on his followers' creativity at both the individual and group level.

The conflicting findings of two of the above studies regarding creativity at the individual level are of particular interest to the present research. Jaussi and Dionne (2003) report that transformational leadership does not relate to individual creative performance of the participating students. This contrasts with the findings of Shin and Zhou (2003), who investigate the effects of transformational leadership on employees' individual-level creativity in a real business setting using a sample of 260 R\&D employees and their supervisors from 46 companies; they found that Korean employees exhibit more creativity under transformational leadership. This inconsistency might readily stem from the different designs of the two studies (experimental vs. real workplace), the different contexts they were conducted in (the U.S. vs. South Korea), and the different samples used (students vs. employees). Therefore, as Mumford and Licuanan (2004) suggest, more studies should investigate in real settings whether transformational leadership positively affects followers' creativity.

The present field study proposes a positive relationship between transformational leadership and followers' individuallevel creativity primarily due to the creativity-enhancing behaviors displayed by this leadership. Second, the fit between this leadership style and the collectivist orientation of Turkish people is likely to strengthen this proposition on the positive direction. In collectivist societies, followers expect their leaders to take care of them while followers are ready to identify with their leaders' vision and demonstrate their loyalty (Bass, 1990a). Bass (1995) argues that transformational leadership is more likely to emerge in collectivist cultures than in the individualistic cultures of the West. Jung and Yammarino (2001) report that the effects of this kind of leadership are stronger among collectivists than among individualists. H1: Transformational leadership relates positively to followers' creativity.

\subsection{Transformational leadership and intrinsic motivation}

Intrinsic motivation refers to the motivational state in which employees are interested in a task for its own sake, rather than for the external outcomes or rewards related to the task (Deci and Ryan, 1985). Intrinsic motivation is one of the most important sources of creativity (Amabile 1983, 1998; Amabile et al., 1996); when an employee is intrinsically attracted to a task, he or she is more likely to focus on it and explore and experiment with it, hence exhibit more creative behavior. Empirical studies have also shown that when employees are intrinsically motivated, they exhibit more creative performance (e.g., Tierney et al., 1999; Jaussi and Dionne, 2003).

Oldham and Cummings (1996) report that supportive supervision is an important determinant of intrinsic motivation and creativity at work. In line with this, transformational leaders who care for their employees' feelings and needs, facilitate their skill development, show them ways to achieve the goals and express confidence in them (Bass, 1990b) are likely to enhance their employees' interest in their tasks. This study expects that employees under this kind of supportive leadership will be intrinsically motivated and ultimately more creative. The challenging vision by this leader's inspirational motivation is likely to enhance the excitement and meaning that employees attribute to their work. The recognition and encouragement that individual consideration by a transformational leader offers are likely to increase the willingness of the employees to focus more and do better in their tasks; and the challenge from this leader's intellectual stimulation is likely to energize the employees to explore and be more attracted to different dimensions of their tasks. According to Amabile (1983), these all lead to an enhancement of interest in the task itself and higher creative achievements.

A few studies test the mediating role of intrinsic motivation. Shin and Zhou (2003) find that intrinsic motivation partially mediated the influence of transformational leadership on followers' creativity. For employees high on conservation (i.e., employees who value conformity, security, and tradition) intrinsic motivation fully mediates this relationship (Shin and Zhou 2003).

Based on the discussion above and the high level of uncertainty avoidance and conservation among Turkish people (Hofstede, 1980), the study proposes that transformational leadership affects followers' creativity through intrinsic motivation. Therefore, H2: Intrinsic motivation mediates the relationship between transformational leadership and followers' creativity.

\subsection{Transformational leadership and psychological empowerment}

Psychological empowerment is another source of creativity (Deci et al., 1989). People who are empowered are more likely to exhibit creative behavior (Jung et al., 2003; Zhou, 1998;). Sheldon (1995) demonstrates that personal autonomy is a core characteristic of creative people, and Mumford and Gustafson (1988) suggest that innovative achievement might increase when organizations support autonomy.

Transformational leadership may increase the psychological empowerment of followers. The transformational leader, by individualized consideration, builds follower self-confidence and heightens personal development, which, in turn, leads to the empowerment of followers (Conger, 1999). Transformational leaders also enhance followers' empowerment by providing meaning and challenge to their work (Avolio et al., 2004); a number of empirical studies confirm this effect (Jung and Sosik, 
2002; Jung et al., 2003). Dvir et al. (2002), in a longitudinal field experiment with Israeli soldiers, also report a positive impact of transformational leadership on followers' empowerment. Consequently, employees under transformational leadership feel empowered and they are likely to seek creative approaches in their jobs. Therefore, H3: Followers' psychological empowerment mediates the relationship between transformational leadership and followers' creativity.

\subsection{Transformational leadership and perception of support for innovation}

The characteristics of their organization largely affect followers' creativity (Siegel and Kaemmerer, 1978; Scott and Bruce, 1994; Amabile et al., 1996). According to Scott and Bruce (1994), organizational climate is an important factor for creativity; employees' perceptions of the extent to which creativity is encouraged at the workplace, and the extent to which organizational resources are allocated to supporting creativity influence creative performance. An employee's perception of an innovative climate encourages risk taking, and the challenge to use creative approaches at work. The present study includes empirically validating this proposition in an R\&D center, where followers' perceptions of an innovative climate enhance their creativity.

Leadership can affect creative behavior through its influence on the followers' perceptions of a climate supportive of innovation. The leader can establish a work environment encouraging creativity (Amabile et al., 1996; Amabile et al., 2004), and create an organizational climate that serves as a guiding principle for more creative work processes (Scott and Bruce, 1994). Transformational leaders, by intellectually stimulating their followers, championing innovation, and articulating a compelling vision throughout their organizations, help establish an organizational climate where employees feel challenged and energized to seek innovative approaches in their jobs. Koene et al. (2002) find that charismatic leadership and consideration have substantial effects on organizational climate. Similarly, Jung et al. (2003) report a significant positive relationship between transformational leadership and innovative organizational climate. Building from these observations, the study proposes the following hypothesis. H4: Followers' perception of support for innovation mediates the relationship between transformational leadership and followers' creativity.

\subsection{Transformational leadership and organizational innovation}

Organizational innovation is the creation of valuable and useful new products/services within an organizational context (Woodman et al., 1993). Since most organizations engage in innovative activity as a competitive weapon, the present study adopts a market-oriented approach and expands this definition to include the returns due to innovation. Accordingly, organizational innovation is the tendency of the organization to develop new or improved products/services and its success in bringing those products/services to the market. This approach is consistent with Damanpour's (1991: 561) definition of product innovations as, "new products/services introduced to meet an external user or market need," and the description provided by the OECD (2004: 64) as, "the successful bringing of the new product or service to the market."

Transformational leaders enhance innovation within the organization; the tendency of organizations to innovate. Leaders' use of inspirational motivation and intellectual stimulation is critical for organizational innovation (Elkins and Keller, 2003). Transformational leaders promote creative ideas within their organizations; this behavior reflects the "championing role" of transformational leaders (Howell and Higgins, 1990). These leaders have a vision that motivates their followers, increases their willingness to perform beyond expectations, and challenges them to adopt innovative approaches in their work. The resulting heightened level of motivation is likely to enhance organizational innovation (Mumford et al., 2002). A number of empirical studies support such leaders' positive impact on innovation (e.g., Keller, 1992; Waldman and Atwater, 1994). These studies examine the relationship between transformational leadership and innovation mostly in R\&D units and at the project level. The proposal of an effect of transformational leadership on innovation at the organizational level has become a topic of empirical research only recently. Jung et al. (2003), in a study of 32 Taiwanese companies, find that transformational leadership significantly and positively relates to organizational innovation as measured by $R \& D$ expenditures and number of patents obtained over the preceding 3 years.

Transformational leaders may also have a positive influence on the market success of the innovations. Leaders who articulate a strong vision of innovation and display a sense of power and confidence will strive to ensure the market success of the innovation. These leaders mobilize their followers to ensure the innovations' success (Jung et al., 2003). Keller (1992) suggests that leading professional employees might require more than traditional leader behaviors especially in R\&D settings where quality rather than quantity is the primary performance criterion. Furthermore, in addition to the internal roles, the transformational leader may be effective in playing external roles such as boundary spanning and entrepreneuring/championing (Howell and Higgins, 1990); these might be important both for understanding the needs of the market and for successful marketing of the innovation. Therefore, this study proposes a positive relationship between transformational leadership and organizational innovation which is conceptualized in this paper as including both the tendency of the organization to innovate and the success of innovations. H5: Transformational leadership relates positively to organizational innovation.

\subsection{Individual creativity and organizational innovation}

The individual is the ultimate source of any new idea (Redmond et al., 1993) and provides the foundation for organizational innovation (Shalley and Gilson, 2004). Hence, theoretically, the creative performance of employees provides the raw material needed for organizational innovation (Oldham and Cummings, 1996). Creative employees are those who tend to identify opportunities for new products. They may find new uses for existing methods or equipments, or generate novel but operable 
work-related ideas. These people not only are more likely to come up with creative solutions to problems and champion ideas to others, but also develop adequate plans for the implementation of new ideas. As Shalley and Gilson (2004) suggest, creative employees produce novel and useful ideas about organizational products, practices, or procedures. Besides, these people might create a spillover effect by serving as role models to the rest of the organization. Shalley et al. (2004) state that creative employees' new ideas are transferable to other employees in the organization for their own use and development. Consequently, such creativity at the individual level, through idea generation and implementation, is likely to lead to the development of innovative products at the organizational level. Creativity of employees positively influences organizational innovation. H6: Individual creativity relates positively to organizational innovation.

\section{Method}

\subsection{Sample}

A total of 163 employees and their leaders in 43 Turkish entrepreneurial software development companies participated in this research. Of the 90 micro- and small-sized information technology companies most of which were located in techno parks, 49 satisfied the two criteria of this study: minimum firm age of 3 years and in-house software development. The leaders of 43 entrepreneurial companies agreed to participate in the study. They were both the owner-managers and immediate supervisors of the R\&D personnel. The leaders provided the names of the R\&D employees engaged in the problem definition and design stages of software development. Of 168 employees identified as explained above, five did not fill out the questionnaire.

The sample is a highly homogeneous one in terms of size of firms and type of task performed. All companies are small with 3 to 17 employees and all are engaged in the development of new products and the improvement of existing products described as development work by Keller (1992). The first reason for selecting such a sample is that it is adequate to investigate both individual-level creativity and organizational innovation. Although the development tasks these companies are engaged in do require creativity (Couger et al., 1993), empirical researchers have neglected the topic of creativity in this industry. Since development work produces incremental innovations (Elkins and Keller, 2003), and software development has an increasing share in industrial innovations (OECD, 1996), the sample is adequate for measuring organizational innovation as well. Second, small entrepreneurial companies when compared with large ones may be more innovative due to their "greater flexibility", and may have "younger and more growth-oriented personnel" (Ettlie, 1983: 29). Moreover, entrepreneurship orientation has been suggested (Kitchell, 1995) and empirically found (Salavou and Lioukas, 2003) to be a driver of innovation.

The sample consists of 130 men $(80 \%)$ and 33 women $(20 \%)$. The average age of the followers is 27.6 years. $4.3 \%$ have high-school diplomas, 71\% have bachelor's degrees, 22\% have master's degrees and 3\% have PhD's. The employees have
2.25 years of average company tenure and 4.71 years of average job tenure in the sector. All participants are Turkish. The average life of the companies is 5.9 years and the average size is 9.4 employees.

\subsection{Procedure}

The fieldwork included interviewing six company owners in the software development industry three times. The aim of the first interview was to understand the specific nature of the development work the companies were engaged in. In the second interview a month later, all participants were provided with items to measure employees' creativity and were asked to identify the ones most relevant to their employees' work. Then, the definition of innovation and the specific descriptions of a technologically new product and improved product adopted in this study were explained. They unanimously agreed that the statements reflected the development work they were engaged in. Finally, participants were provided with the measures of organizational innovation commonly used in empirical research (such as number of patents and R\&D intensity) and were asked to recommend measures for their industry. The authors took these comments and recommendations into consideration when developing the measure of organizational innovation which was then presented to the leaders in the third interview. The participants agreed with the measure without exception.

Data were collected by two separate questionnaires: one for the employees and the other for their leaders. The questionnaires included company and employee identification codes so that data collected from the leaders and employees could be matched and grouped for analysis. All respondents were guaranteed confidentiality. The questionnaires were given in envelopes and employees were told to seal their completed forms. They were collected immediately after completion. All of the questionnaires were completed during regular working hours and the authors were present to answer questions and collect the completed surveys. Since all the participants were Turkish, the questionnaire items (except the MLQ for which the copyright had been obtained for the Turkish version) were carefully translated and back-translated to ensure conceptual equivalence and comparability (Brislin, 1986).

Employees' questionnaires included measures of transformational leadership, perception of support for innovation, psychological empowerment, and intrinsic motivation. On average, 4 employees rated each leader. Employees were also asked their age, gender, educational level, job tenure, and company tenure.

Leaders' questionnaires were administered in two separate visits, within a one-month interval. In the first visit, leaders were asked to provide data on company innovations. They were also asked for the age of their firms. In the second visit, they evaluated their employees' creativity. The reason for conducting the leaders' questionnaire at two separate times was to prevent any bias or inflated results that might have arisen if the leaders had answered the questions about organizational innovation and creativity of their subordinates at the same time. The average number of employees evaluated by each leader was 4 . 


\subsection{Individual-level measures}

\subsubsection{Transformational leadership}

This study measured transformational leadership using twenty items from the Turkish version of the Multi-Factor Leadership Questionnaire (MLQ-Form 5X) (Bass and Avolio, 1995). Avolio et al. (1999) provide support for the convergent and discriminant validity of the instrument. If subordinates provided both the transformational leadership ratings and the criterion ratings, the results could have been potentially biased by same-source (MLQ) data. Therefore, only the transformational leadership items were used from the questionnaire. Participants judged how frequently their immediate leader engaged in transformational leadership behaviors. Ratings were completed on a 5-point scale with 1 representing "Not at all" and 5 representing "Frequently, if not always". Sample items included: "Articulates a compelling vision of the future," "Treats me as an individual rather than as a member of the group," and "Gets me to look at problems from many different angles."

Exploratory factor analysis using the principal components method and varimax rotation was conducted on the twenty items in order to determine their factor structure. After two items with factor loadings less than 0.50 were removed, the resulting eighteen items loaded on one factor, which accounted for $47 \%$ of the variance. These items were averaged to form a scale. Reliability (i.e., Cronbach's alpha) of the scale was 0.93 . Bycio et al. (1995) show that the dimensions of transformational leadership fail to exhibit discriminant validity in predicting outcomes. Furthermore, since this study did not have any a priori expectation that individual dimensions of transformational leadership would differentially affect creativity and innovation, a single index was used to measure transformational leadership. Prior research (Judge and Bono, 2000) validates the use of a single scale to represent transformational leadership.

\subsubsection{Intrinsic motivation}

Intrinsic motivation was measured by five items adapted from Tierney et al. (1999). On a five point scale ranging from 1 ("Corresponds not at all") to 5 ("Corresponds exactly"), employees indicated the extent to which each of the statements applied to them in terms of their current tasks. Sample items were "I enjoy coming up with new ideas for products" and "I enjoy improving existing processes or products." These five items loaded on one factor and explained $55.24 \%$ of the variance. They were averaged to form a scale with a reliability of 0.77 .

\subsubsection{Psychological empowerment}

Psychological empowerment was measured by the 12-item scale developed by Spreitzer (1995). All items were rated using a 5-point scale ranging from 1 ("Very strongly disagree") to 5 ("Very strongly agree"). Sample items were "I have significant influence on what happens in my department" and "I have significant autonomy in determining how I do my job." Exploratory factor analysis revealed that six items had factor loadings less than 0.50 . After they were removed, the resulting six items loaded on one factor, which accounted for $52.59 \%$ of the variance. These items were averaged to form a scale, which had a reliability of 0.82 .

\subsubsection{Perception of support for innovation}

This variable was measured by 12 items adapted from Scott and Bruce (1994). On a 5-point scale ranging from 1 ("Strongly disagree") to 5 ("Strongly agree"), employees indicated the extent to which their companies supported creativity. Sample items were "This organization can be described as flexible and continually adapting to change" and "There are adequate resources devoted to innovation in this organization." Based on the factor analysis results, three items with loadings less than 0.50 were removed. The remaining 9 items loaded on one factor that accounted for $55.40 \%$ of the variance. These items were averaged to form a scale with a reliability of 0.88 .

\subsubsection{Creativity}

Followers' creativity is the dependent variable of the first part of the study. The subject of investigation in the present research is the creativity of the employees who are working in $R \& D$ departments and are expected to turn creative ideas into innovative products; thus, both idea generation and implementation by these employees should be considered in measuring creativity (Mumford et al., 2002). We adapted 13 items that capture these two concepts from Tierney et al. (1999) and Zhou and George's (2001) creativity measures.

Leaders evaluated the creativity of their employees one month after the employees rated their leadership behavior. On a five point scale ranging from 1 ("Not at all characteristic") to 5 ("Very characteristic"), leaders were asked to report how often each of their employees could be described according to the items. Sample items were "Promotes and champions ideas to others" and "Serves as a good role model for creativity." All of the items loaded on one factor, which accounted for $62.99 \%$ of the variance. The items were averaged to form a scale with a reliability of 0.95 .

\subsubsection{Control variables}

Followers' educational level and job tenure are the control variables of this study since they are related to creativity. Creativity is the outcome of an individual's accumulated creative thinking skills and expertise based on formal education and past experience (Amabile, 1998). Furthermore, experience provides a level of familiarity which might be needed for creative performance (Shalley and Gilson, 2004). Therefore, job tenure was used as an indicator of experience.

\subsection{Organizational-level measures}

\subsubsection{Transformational leadership and creativity at the organizational level}

Consistent with Shamir et al. (1998), this study treats transformational leadership as an organizational-level variable; in other words, as leadership behaviors exhibited to the organization, a micro- or a small-sized company here, as a whole. Therefore, transformational leadership ratings by the subordinates were aggregated to the organizational level by averaging 
their values for each organization. In addition, in order to test the hypotheses regarding organizational innovation, creativity ratings of the subordinates by their leaders were aggregated to the organizational level by averaging their values for each organization.

One-way ANOVA provided empirical justification for aggregating subordinate ratings of transformational leadership. The results showed that between-group differences were significantly higher than within-group differences $(F=3.06$, $p<0.001)$. Intra-class correlation ICC 1 was 0.52 and ICC2 was 0.67 . The inter-rater reliability $\left(r_{\mathrm{wg}(\mathrm{j})}\right)$ (James et al., 1984) for subordinates' rating the same leader was also examined. The mean $r_{\mathrm{wg}(\mathrm{j})}$ value for the transformational leadership ratings was 0.96 and the median was 0.97 . These results showed that aggregation was appropriate for this variable.

\subsubsection{Organizational innovation}

This study defines organizational innovation as the tendency of the organization to develop new or improved products/services and its success in bringing those products/services to the market. Consistent with this definition and taking into consideration the comments the leaders made during the interview, a new criterion for measuring organizational innovation was developed. The leaders' common concern was that quantifiable measures such as copyrights or quality certificates commonly employed to study established companies in developed industries and countries might not be applicable either to the growing software development industry or to the nature of competition among small-sized entrepreneurial companies in Turkey, because the rules of competition and the legal structure are poorly established. Therefore, a market-oriented approach rather than such quantifiable input measures was adopted for developing the measurement of organizational innovation.

The measure of organizational innovation in this study is the product of two ratios, namely, the coefficient of innovativeness tendency and the success of product innovations. Coefficient of innovativeness tendency is the ratio of sales generated by product innovations to total sales. This coefficient quantifies the innovativeness orientation of companies engaged in other work apart from software development such as marketing computer hardware. This measure of innovative activity was also used by Czarnitzki and Kraft (2004), who investigated the innovative performance of European firms. In order to operationalize the definition of organizational innovation in this study, this measure was employed as a coefficient to modify the success of product innovations.

Success of product innovations is the ratio of sales generated by product innovations to the expenditures in producing those product innovations. This ratio shows the success of the organization in both satisfying market needs and utilizing the organization's resources in producing the innovations. This is a better measure of outcomes than the R\&D expenditures measured in absolute numbers. As stated by Jung et al. (2003: 540), expenditures for innovation itself do not reflect the success of the company in generating "outcomes," but rather its "willingness" to support innovation.

New products developed and existing products improved (Keller and Holland, 1983; Woodman et al., 1993) as well as custom-made projects (OECD, 1996) by the companies are regarded as product innovations in this research. The questionnaire administered to the leaders included the definition of innovation (Keller and Holland, 1983) and descriptions by the OECD (1996) of new and improved products along with examples of innovation in the software development industry (provided in the Appendix). The leaders analyzed every product and custom-made project of their company to determine whether it would be considered an innovation according to the guidelines. They answered three questions: total sales generated by product innovations during the previous three years, total sales of the company during the previous three years, and total expenditures in producing those product innovations during the same time period. The output questions covered the last three years to take into account the newly emerging nature of this market in Turkey where software development and sales might take longer.

\subsubsection{Control variable}

Firm age is the control variable in this part of the study, since prior studies report its positive relationship with organization innovation (Hitt et al., 1997; Jung et al., 2003).

\section{Results}

\subsection{Individual-level analysis}

\subsubsection{Descriptive statistics}

Table 1 includes means, standard deviations, alpha coefficients, and correlations among all individual-level variables. Intercorrelations show that creativity significantly and positively correlates with transformational leadership $(r=0.17$, $p<0.05)$, intrinsic motivation $(r=0.24, p<0.01)$, and psychological empowerment $(r=0.24, p<0.01)$, but not with perception of support for innovation $(r=0.10$, n.s.). Transformational leadership has significant positive correlations with intrinsic motivation $(r=0.31, p<0.001)$, psychological empowerment $(r=0.27, p<0.001)$, and perception of support for innovation $(p=0.71, p<0.001)$.

\subsubsection{Tests of individual-level hypotheses}

Hypotheses 1 through 4 relate to the direct effect of transformational leadership on employee creativity and the mediators of this relationship. These hypotheses are tested using Hierarchical Linear Modeling (HLM) because the data of this study are nested within organizations, and the model includes cross-level relationships between transformational leadership (organizational-level), mediators (individual-level), and employee creativity (individual-level). HLM accounts for dependence among the scores for individuals within the same group and accommodates variables at multiple levels (Bryck and Raudenbush, 1992). Building from suggestion by Hofmann and Gavin (1998) all HLM analyses use grand-mean centering.

In order to test the direct and mediated effects, the study uses the multilevel mediational modeling method (Krull and MacKinnon, 2001). This method incorporates Baron and Kenny's (1986) mediational analysis procedure into 
Table 1

Descriptive statistics, alpha coefficients, and correlations: individual-level scales

\begin{tabular}{|c|c|c|c|c|c|c|c|c|}
\hline Variable & Mean & S.D. & 1 & 2 & 3 & 4 & 5 & 6 \\
\hline 1. Transformational leadership & 3.9 & 0.68 & $(0.93)$ & & & & & \\
\hline 2. Intrinsic motivation & 4.4 & 0.65 & $0.31 * * *$ & $(0.77)$ & & & & \\
\hline 3. Psychological empowerment & 3.4 & 0.73 & $0.27 * * *$ & $0.31 * * *$ & $(0.82)$ & & & \\
\hline 4. Perception of support for innovation & 3.7 & 0.80 & $0.71 * * *$ & $0.35 * * *$ & $0.31 * * *$ & $(0.88)$ & & \\
\hline 5. Creativity & 3.7 & 0.78 & $0.17 *$ & $0.24 * *$ & $0.24 * *$ & 0.10 & $(0.95)$ & \\
\hline 6. Education & - & - & -0.10 & 0.06 & $0.19 *$ & -0.10 & 0.12 & - \\
\hline 7. Job tenure & 4.7 & 4.18 & -0.12 & 0.03 & $0.19 *$ & -0.05 & 0.06 & -0.04 \\
\hline
\end{tabular}

$n=163$.

Alpha coefficients are on the diagonal, in parentheses.

$* p<0.05$.

$* * p<0.01$.

$* * * p<0.001$.

hierarchical linear models. The method also includes the test of the direct effects in addition to the mediated effects. According to the method, three conditions are necessary to establish mediation. First, the independent variable (transformational leadership) should significantly relate to the dependent variable (creativity). Second, the independent variable should significantly relate to the mediator. Third, when the dependent variable is regressed on both the independent variable and the mediator, the mediator should significantly relate to the dependent variable and the independent variable should not significantly relate to the dependent variable. Full mediation occurs when the direct effect of the independent variable in this last condition is reduced to zero, otherwise the mediating effect is partial. To determine whether the mediated effect is significant, Sobel test for multilevel mediational modeling method (Krull and MacKinnon, 2001) is used. Educational level and job tenure of the employees are controlled for in all the hierarchical models. Table 2 summarizes the results of this analysis.

Hypothesis 1 states that there is a positive relationship between transformational leadership and individual creativity. As the table shows, there is a significant positive relationship between transformational leadership and creativity $\left(\gamma_{01}=0.25\right.$, $p<0.05$ ), after controlling for education and job tenure. Therefore, the findings support Hypothesis 1. This significant relationship also satisfies the first condition of the mediation tests for all three mediators.

Hypothesis 2 suggests that intrinsic motivation mediates the relationship between transformational leadership and individual creativity. According to the results in Table 2, transformational leadership has a significant association with intrinsic motivation $\left(\gamma_{01}=0.22, p<0.05\right)$. In addition, intrinsic motivation significantly relates to creativity $\left(\gamma_{10}=0.28, p<0.05\right)$ when entered together with transformational leadership into the equation predicting creativity, where transformational leadership has no significant effect $\left(\gamma_{01}=0.19\right.$, n.s.). These results suggest a partial mediating effect of intrinsic motivation. However, the result of the Sobel test indicates that intrinsic motivation does not significantly reduce the effect of transformational leadership on creativity $(t=1.66$, n.s.). Since intrinsic motivation does not significantly mediate the relationship between transformational leadership and creativity, the findings do not support Hypothesis 2.
Hypothesis 3 predicts a mediating effect of psychological empowerment for the relationship between transformational leadership and individual creativity. The results show that

Table 2

Results of the multilevel mediational analysis

\begin{tabular}{|c|c|c|c|c|}
\hline & Creativity & $\begin{array}{l}\text { Intrinsic } \\
\text { motivation }\end{array}$ & $\begin{array}{l}\text { Psychological } \\
\text { empowerment }\end{array}$ & $\begin{array}{l}\text { Perception of } \\
\text { support for } \\
\text { innovation }\end{array}$ \\
\hline Education & $0.19(0.10)$ & & & \\
\hline Job tenure & $0.02(0.01)$ & & & \\
\hline $\begin{array}{l}\text { Transformational } \\
\text { leadership }\end{array}$ & $0.25 *(0.10)$ & & & \\
\hline Education & & $0.09(0.06)$ & & \\
\hline Job tenure & & $0.01(0.01)$ & & \\
\hline $\begin{array}{l}\text { Transformational } \\
\text { leadership }\end{array}$ & & $0.22 *(0.10)$ & & \\
\hline Education & $0.16(0.10)$ & & & \\
\hline Job tenure & $0.02(0.01)$ & & & \\
\hline $\begin{array}{l}\text { Transformational } \\
\text { leadership }\end{array}$ & $0.19(0.10)$ & & & \\
\hline $\begin{array}{l}\text { Intrinsic } \\
\text { motivation }\end{array}$ & $0.28 *(0.11)$ & & & \\
\hline Education & & & $0.25 *(0.12)$ & \\
\hline Job tenure & & & $0.04 * * *(0.01)$ & \\
\hline $\begin{array}{l}\text { Transformational } \\
\text { leadership }\end{array}$ & & & $0.31 * *(0.09)$ & \\
\hline Education & $0.19(0.12)$ & & & \\
\hline Job tenure & $0.00(0.01)$ & & & \\
\hline $\begin{array}{l}\text { Transformational } \\
\text { leadership }\end{array}$ & $0.16(0.08)$ & & & \\
\hline $\begin{array}{l}\text { Psychological } \\
\text { empowerment }\end{array}$ & $0.29 * *(0.11)$ & & & \\
\hline Education & & & & $-0.10(0.08)$ \\
\hline Job tenure & & & & $0.00(0.01)$ \\
\hline $\begin{array}{l}\text { Transformational } \\
\text { leadership }\end{array}$ & & & & $0.95 * * *(0.09)$ \\
\hline Education & $0.20(0.11)$ & & & \\
\hline Job tenure & $0.02(0.01)$ & & & \\
\hline $\begin{array}{l}\text { Transformational } \\
\text { leadership }\end{array}$ & $0.21(0.12)$ & & & \\
\hline $\begin{array}{l}\text { Perception of } \\
\text { support for } \\
\text { innovation }\end{array}$ & $0.03(0.08)$ & & & \\
\hline
\end{tabular}

Results are Hierarchical Linear Modeling-derived parameters.

Values in parentheses are the standard errors of the coefficients. $* p<0.05$.

$* * p<0.01$.

$* * * p<0.001$. 
the conditions required for a mediator effect are satisfied. Transformational leadership significantly relates to psychological empowerment $\left(\gamma_{01}=0.31, p<0.01\right)$. Psychological empowerment significantly associates with creativity $\left(\gamma_{10}=0.29, p<0.01\right)$ when entered together with transformational leadership into the equation predicting creativity, where transformational leadership has no significant effect $\left(\gamma_{01}=0.16\right.$, n.s. $)$. The results of the Sobel test also indicate a significant mediated relationship $(t=2.09, p<0.05)$. These suggest that psychological empowerment partially mediates the relationship between transformational leadership and creativity. Therefore, the findings support Hypothesis 3.

Hypothesis 4 states that perceived support for innovation mediates the relationship between transformational leadership and individual creativity. As shown in Table 2, there is a significant association between transformational leadership and perception of support for innovation $\left(\gamma_{01}=0.95, p<0.001\right)$. However, perception of support for innovation does not significantly relate to creativity $\left(\gamma_{10}=0.03\right.$, n.s. $)$ when entered together with transformational leadership into the equation predicting creativity. Since the third condition is not satisfied, perception of support for innovation does not mediate the relationship between transformational leadership and creativity. Therefore, Hypothesis 4 is not supported.

\subsection{Organizational-level analysis}

\subsubsection{Descriptive statistics}

Table 3 presents means, standard deviations, and correlations among organizational-level variables. Organizational innovation has a significant correlation with transformational leadership $(r=0.30, p<0.05)$, but not with creativity.

\subsubsection{Tests of organizational-level hypotheses}

Hypotheses 5 and 6 relate to the direct effects of transformational leadership and creativity on organizational innovation. These hypotheses are tested by regression analysis. The control variable (firm age) is entered first as a predictor of innovation. Then, the main effects predictor variables (transformational leadership and creativity) are entered into the regression equation. Table 4 presents the results of this analysis.

Hypothesis 5 predicts a positive relationship between transformational leadership and organizational innovation. Results of the analysis reveal that, after controlling for firm age, transformational leadership has a significant positive effect on organizational innovation $(b=0.40, p<0.05)$. Therefore, Hypothesis 5 is supported.

\section{Table 3}

Descriptive statistics, and correlations: organizational-level variables

\begin{tabular}{|c|c|c|c|c|c|c|}
\hline Variables & Mean & S.D. & 1 & 2 & 3 & 4 \\
\hline 1. Firm age & 5.9 & 3.73 & & & & \\
\hline 2. Transformational leadership & 3.9 & 0.53 & -0.11 & & & \\
\hline 3. Creativity & 3.7 & 0.50 & -0.13 & 0.29 & & \\
\hline 4. Organizational innovation & 1.6 & 0.56 & 0.29 & 0.30 * & -0.08 & \\
\hline
\end{tabular}

Table 4

Results of the regression analysis for organizational innovation

\begin{tabular}{|c|c|c|}
\hline & Step 1 & Step 2 \\
\hline Firm age & 0.04 & $0.05 *$ \\
\hline Transformational leadership & & $0.40 *$ \\
\hline Creativity & & -0.17 \\
\hline$F$ & 3.68 & $3.52 *$ \\
\hline$D f$ & 1 & 3 \\
\hline$R^{2}$ & 0.08 & 0.21 \\
\hline$\Delta R^{2}$ & & $0.13 *$ \\
\hline
\end{tabular}

Hypothesis 6 states that creativity positively relates to organizational innovation. Since creativity does not have a significant relationship with organizational innovation $(b=-0.17$, n.s.), Hypothesis 6 is not supported.

\section{Discussion}

This paper has both theoretical and methodological contributions to the literature. This study is the first to investigate the effects of transformational leadership on creativity-related outcomes at multiple levels within organizations. The findings suggest that transformational leadership has important effects at both individual and organizational levels. At the individual level, transformational leadership positively relates to followers' creativity. This finding is valuable for two reasons. First, previous findings were inconsistent and further research in real settings was needed to support the positive proposition in favor of this leadership (Mumford and Licuanan, 2004). In line with the findings of Shin and Zhou (2003), this research, conducted in real-work settings, finds a positive relationship between transformational leadership and followers' individual creativity. Second, this positive relationship exists in collectivist Turkey (Hofstede, 1980), supporting the arguments by Bass (1990a) that transformational leadership is more likely to emerge in collectivist cultures than in the individualist cultures of the West and that collectivists perform better under transformational leadership. A number of studies report a stronger positive effect of transformational leadership on the creative performance of collectivists as compared to individualists (e.g., Jung and Avolio, 1999; Jung and Yammarino, 2001).

Analysis of the mediators reveals partial mediating effects for intrinsic motivation and psychological empowerment based on Baron and Kenny's (1986) criteria. Yet, the test of mediation shows that intrinsic motivation is not a significant mediator of the transformational leadership-creativity relationship. This finding seems to contradict Shin and Zhou's (2003) study that shows a partial mediating effect of intrinsic motivation. However, their research does not involve a formal test of the significance of this mediated effect, making it difficult to comment on these inconsistent results.

The mediating effect of psychological empowerment, on the other hand, is significant. This finding is an important contribution to the literature in that it shows psychological empowerment as a crucial psychological mechanism through which transformational leadership influences employees' creativity. A reason for 
psychological empowerment to be a stronger mediator than intrinsic motivation might be that R\&D employees are already intrinsically motivated, which may act as a substitute for the influence of a transformational leader on their creative performance. This leader's effect through enabling them to make their own decisions and take initiatives might be a more powerful creativity-enhancing force for these employees than his or her effect through influencing their intrinsic motivation.

Contrary to the expectation of this study, the mediating role of perception of support for innovation is not significant. This finding might have resulted from the high correlation between transformational leadership and support for innovation $(r=0.71)$. In addition, the transformational leader's direct behavior on employees, such as individualized consideration and intellectual stimulation, might affect their emotional well-being and provide direct and clear cues that creative behavior is expected; whereas, employees might not take an innovation supporting climate, an organization-wide contextual factor, as personally. These arguments might apply more to a high power-distance culture, where the workers put more value on their leader's building one-to-one relationships with them. The increased enthusiasm might make them seek more innovative approaches in their work. Perhaps Turkish people, who rank high on power-distance (Hofstede, 1980), respond readily to the transformational leader who empower them, but they may not see a climate supporting innovation as important to them personally.

At the organizational level of analysis, in line with the findings of Jung et al. (2003), this study reports that transformational leadership has a significant positive association with organizational innovation. Moreover, as stated before, previous research focused on this leader's effect on the tendency of organizations to innovate. The definition of organizational innovation in this study includes the success of innovations as well as the tendency to innovate. The findings suggest that transformational leaders might not only promote innovative activity within the organization but also ensure the market success of the innovations. Furthermore, since the innovations under investigation here are related to development work, the positive influence of this form of leadership is identified on incremental innovation. This finding somewhat contradicts Keller's (1992) suggestion that developmental projects which use existing knowledge to produce incremental innovations might need more of a transactional leader to allocate and coordinate tasks, while research projects which need originality and importation of technical information in order to produce radical innovation might be better led by transformational leaders. Transactional leadership is not under investigation here, but this study suggests that as the transformational character of the leader increases, innovation in developmental work increases. This contrary result might have stemmed from the collectivist character of the Turkish participants who would expect their leaders to exhibit transformational leader behaviors (Bass, 1995) and would readily respond to transformational leadership.

The proposed relationship between individual-level creativity and organizational innovation is not significant. Several reasons might explain this finding. First, as Mumford and Gustafson (1988) suggest, employee creativity may be necessary but not sufficient for organizational innovation given that creative ideas or solutions might not be considered useful or might not be successfully implemented. In this case, they will not be converted into actual innovations in the organization. Furthermore, Perry-Smith and Shalley (2003) argue that novel information is less likely to be communicated through stronger ties (good friends or close relationships) than weaker ties (more distant relationships or distant colleagues). Given that R\&D groups under investigation in this study are composed of a handful of employees stronger ties might have been in effect leading to less communication of novel information. Moreover, creative output of a collective may be a function of not only the creativity of individuals but also group processes such as group cohesion (Woodman et al., 1993), effective communication by group members (Taggar, 2002), and team integration skills such as conflict resolution and collaborative problem-solving skills (Janssen et al., 2004). The lack of these factors or even a low level of them might hinder the effects of individual creativity (Taggar, 2002). This might have been the case in the present study. Finally, the methodology employed here might have been a reason for the failure to find this relationship. In this study, there is a mismatch between the 3-year period for which innovation data were measured and the company tenures of the participants, which average 2.25 years. Therefore, participant employees might not have contributed to the innovative projects of the last 3 years.

The methodological contributions of this study are twofold. First, this study investigates transformational leadership, creativity, and innovation in Turkey, a developing country; it shows the external validity of these theories which were developed and tested in Western developed countries. Second, the market-oriented measure developed and used as a proxy for organizational innovation in this study qualifies as a methodological contribution. It can be used as a measure of innovation in newly developing industries and in entrepreneurial companies, especially in underdeveloped or developing countries where quantifiable measures such as patents or copyrights are not relevant. Furthermore, this measure differs from other measures of organizational innovation in that it reflects not only the firms' propensity to innovate but also the returns on innovations, an important indicator of competitive advantage.

This study is not without its limitations. Employees' creativity was evaluated only by their leaders and this might have led to artificially inflated ratings. Another limitation is the crosssectional design employed; which makes it difficult to infer causality between the variables in such studies. The significant relationships reported in this study are associative and correlational, and may not be causal. For example, the positive relationship between transformational leadership and creativity might have been a spurious one due to some contextual factors that influence these variables. Thus, longitudinal studies in realwork settings can better analyze the significant relationships found here. In addition, the sample of this study might be another limitation. First, the sample is primarily comprised of males. Second, it includes small-sized entrepreneurial software development companies operating in Turkey. The findings might not be generalizable to other software development companies or to 
other types of organizations in different industries and/or countries. Finally, this research does not include group characteristics or processes such as group composition, cohesiveness, and communication while investigating individual creativity-organizational innovation relationships, which might have prevented capturing the complexity of this relationship.

\subsection{Directions for future research}

This study focuses on the mediating processes underlying the relationship between transformational leadership and followers' creativity. Future research might examine the processes that mediate the relationship between this leadership and organizational innovation. In addition, studies should investigate whether psychological empowerment is a significant mediator of the transformational leadership-employee creativity relationship in different countries or industries. Moreover, this study does not support the effect of individual creativity on organizational innovation. Future research should examine whether the mediating and moderating influences of group processes such as cohesiveness, diversity, and conflict are the determinants of organizational innovation rather than employees' creativity.

The measure of organizational innovation that this study develops and uses might be useful for studies in industries other than software development, or in industries which produce radical innovation. Studies in different countries can also use this measure in order to evaluate its external validity.

\subsection{Implications for managerial practice}

This research is the first to investigate transformational leadership and its effects on creativity and organizational innovation in Turkey. Equally important, it is conducted in entrepreneurial companies in the software development industry. This sector is particularly important for Turkey, because of its low standing in the world development average (DPT, 2001). All stakeholders, especially managers, should encourage the development and competitiveness of this industry.

The findings of this study should encourage managers to stimulate their followers by empowering them. They should understand that this mechanism significantly enhances their employees' creative performance. The findings should also encourage them to engage in transformational leadership behaviors in order to boost the creative performance of their employees and to bring about organizational innovation. Findings of this study also provide evidence that transformational leadership should be the subject of management training and development in Turkey to improve the innovation performance of the country.

\section{Appendix A. Descriptions and examples of innovation provided to the leaders}

Innovation. Innovation is an important product, process, or idea leading to a new or improved product that is new to the organization. According to this definition, new products developed, existing products improved, and custom-made projects which display significantly different attributes from the firms' previous products are considered as product innovations in this study.

\section{Technological product innovation}

The term "product" covers both goods and services. Technological product innovation can take two broad forms: A technologically new product is a product whose technological characteristics or intended uses differ significantly from those of previously produced products. Such innovations can involve radically new technologies, can be based on combining existing technologies in new uses, or can be derived from the use of new knowledge. A technologically improved product is an existing product whose performance has been significantly enhanced or upgraded. A simple product may be improved (in terms of better performance or lower cost) through the use of higherperformance components or materials; or a complex product which consists of a number of integrated sub-systems may be improved by partial changes to one of the sub-systems.

Examples of technological innovations in software development companies. The introduction of new multimedia software applications that can be used for educational purposes, thus eliminating the need for a live human instructor. The development of a whole range of different customer packages in which clients are offered varying degrees of assistance/support.

\section{References}

Amabile TM. The social psychology of creativity. New York: Springer-Verlag; 1983.

Amabile TM. How to kill creativity. Harvard Business Review 1998;76(5):77-87.

Amabile TM, Conti R, Coon H, Lazenby J, Herron M. Assessing the work environment for creativity. Academy of Management Journal 1996;39(5): 1154-84.

Amabile TM, Schatzel EA, Moneta GB, Kramer SJ. Leader behaviors and the work environment for creativity: perceived leader support. Leadership Quarterly 2004;15(1):5-32.

Avolio BJ, Bass BM, Jung DI. Re-examining the components of transformational and transactional leadership using the Multifactor Leadership Questionnaire. Journal of Occupational and Organizational Psychology 1999;72(4):441-63.

Avolio BJ, Zhu W, Koh W, Bhatia P. Transformational leadership and organizational commitment: mediating role of psychological empowerment and moderating role of structural distance. Journal of Organizational Behavior 2004;25:951-68.

Baron RM, Kenny DA. The moderator-mediator variable distinction in social psychological research: conceptual, strategic, and statistical considerations. Journal of Personality and Social Psychology 1986;53:561-71.

Bass BM. Leadership and performance beyond expectations. New York: The Free Press; 1985.

Bass BM. Bass and Stogdill's handbook of leadership: theory, research, and managerial applications. 3rd ed. New York: The Free Press; 1990a.

Bass BM. From transactional to transformational leadership: learning to share the vision. Organizational Dynamics 1990b;18(3):19-32.

Bass BM. Transformational leadership. Journal of Management Inquiry 1995;4(3): 293-8.

Bass BM, Avolio BJ. MLQ, Multifactor Leadership Questionnaire. 2nd ed. Redwood City, CA: Mind Garden; 1995.

Brislin R. The wording and translation of research instruments. In: Lonner WJ, Berry JW, editors. Field methods in cross-cultural research. Beverly Hills, CA: Sage; 1986. p. 137-64.

Bryck AS, Raudenbush SW. Hierarchical linear models: application and data analysis methods. London: Sage; 1992. 
Burns JM. Leadership. New York: Harper \& Row; 1978.

Bycio P, Hackett RD, Allen JS. Further assessment of Bass's (1985) conceptualization of transactional and transformational leadership. Journal of Applied Psychology 1995;80:468-78.

Conger JA. Charismatic and transformational leadership in organizations: an insider's perspective on these developing streams of research. Leadership Quarterly 1999;10(2):145-79.

Couger JD, Higgins LF, Mclntyre SC. Unstructured creativity in information systems organizations. MIS Quarterly 1993;17(4):375-97.

Czarnitzki D, Kraft K. Firm leadership and innovative performance: evidence from seven EU countries. Small Business Economics 2004;22:325-32.

Damanpour F. Organizational innovation: a meta-analysis of effects of determinants and moderators. Academy of Management Journal 1991;34: 555-90.

Deci EL, Ryan RM. Intrinsic motivation and self-determination in human behavior. New York: Plenum Press; 1985.

Deci EL, Connell JP, Ryan RM. Self-determination in a work organization. Journal of Applied Psychology 1989;74(4):580-90.

DPT (The State Planning Organization of Turkey). Ad hoc committee report on information technologies and policies; 2001. http://www.ekutup.dpt.gov.tr/ bilisim/oik576.pdf.

Drucker PF. Innovation and entrepreneurship: practice and principles. New York: Harper and Row, Publishers; 1985.

Dvir T, Eden D, Avolio BJ, Shamir B. Impact of transformational leadership on follower development and performance: a field experiment. Academy of Management Journal 2002;45(4):735-44.

Elkins T, Keller RT. Leadership in research and development organizations: a literature review and conceptual framework. Leadership Quarterly 2003;14: 587-606.

Ettlie JE. Organizational policy and innovation among suppliers to food processing sector. Academy of Management Journal 1983;26(1):27-44.

Hitt MA, Hoskisson RE, Kim H. International diversification: effects on innovation and firm performance in product-diversified firms. Academy of Management Journal 1997;40(4):767-98.

Hofmann DA, Gavin MB. Centering decisions in hierarchical linear models: implications for research in organizations. Journal of Management 1998;24: 623-41.

Hofstede G. Culture's consequences: international differences in work-related values. Beverly Hills, CA: Sage; 1980.

Howell JM, Higgins CA. Champions of technological innovation. Administrative Science Quarterly 1990;35:317-41.

Howell JM, Avolio BJ. Transformational leadership, transactional leadership, locus of control, and support for innovation. Journal of Applied Psychology 1993;78(6): 891-902.

Hunt JG, Stelluto GE, Hooijberg R. Toward new-wave organization creativity: beyond romance and analogy in the relationship between orchestra-conductor leadership and musician creativity. Leadership Quarterly 2004;15:145-62.

James LR, Demaree RG, Wolf G. Estimating within-group inter-rater reliability with and without response bias. Journal of Applied Psychology 1984;69: 85-98.

Janssen O, Van der Vliert E, West M. The bright and dark sides of individual and group innovation: a special issue introduction. Journal of Organizational Behavior 2004;25:129-45.

Jaussi KS, Dionne SD. Leading for creativity: the role of unconventional leader behavior. Leadership Quarterly 2003;14:475-98.

Judge TA, Bono JE. Five-factor model of personality and transformational leadership. Journal of Applied Psychology 2000;85:751-65.

Jung DI. Transformational and transactional leadership and their effects on creativity in groups. Creativity Research Journal 2001;13(2):185-95.

Jung DI, Avolio BJ. Effects of leadership style and followers' cultural orientation on performance in group and individual task conditions. Academy of Management Journal 1999;42(2):208-18.

Jung DI, Yammarino FJ. Perceptions of transformational leadership among Asian Americans and Caucasian Americans: a level of analysis perspective. The Journal of Leadership Studies 2001;8(1):3-21.

Jung DI, Sosik J. Transformational leadership in work groups: the role of empowerment, cohesiveness and collective efficacy on perceived group performance. Small Group Research 2002;33:313-36.
Jung DI, Chow $\mathrm{C}, \mathrm{Wu} \mathrm{A}$. The role of transformational leadership in enhancing organizational innovation: hypotheses and some preliminary findings. Leadership Quarterly 2003;14:525-44.

Kahai SS, Sosik JJ, Avolio BJ. Effects of leadership style, anonymity, and rewards on creativity-relevant processes and outcomes in an electronic meeting system context. Leadership Quarterly 2003;14:499-524.

Keller RT. Transformational leadership and the performance of research and development project groups. Journal of Management 1992;18(3):489-501.

Keller RT, Holland WE. Communicators and innovators in research and development organizations. Academy of Management Journal 1983;26(4): 742-9.

Kitchell S. Corporate culture, environmental adaptation, and innovation adoption: a qualitative/quantitative approach. Journal of the Academy of Marketing Science 1995;23(3):195-205.

Koene BAS, Vogelaar ALW, Soeters JL. Leadership effects on organizational climate and financial performance: local leadership effect in chain organizations. Leadership Quarterly 2002;13:193-215.

Krull JL, MacKinnon DP. Multilevel modeling of individual and group-level mediated effects. Multivariate Behavioral Research 2001;36:249-77.

Lowe KB, Kroeck GK, Sivasubramaniam N. Effectiveness correlates of transformational and transactional leadership: a meta-analytic review of the MLQ Literature. Leadership Quarterly 1996;7(3):385-425.

Mumford MD, Gustafson SB. Creativity syndrome: integration, application, and innovation. Psychological Bulletin 1988;103(1):27-43.

Mumford MD, Scott GM, Gaddis B, Strange JM. Leading creative people: orchestrating expertise and relationships. Leadership Quarterly 2002;13(6): $705-50$.

Mumford MD, Licuanan B. Leading for innovation: conclusions, issues, and directions. Leadership Quarterly 2004;15(1):163-71.

OECD. The measurement of scientific and technological activities: proposed guidelines and interpreting technological innovation data (Oslo Manual); 1996. http://www.oecd.org/dataoecd/35/61/2367580.pdf.

OECD. Small and medium-sized enterprises in Turkey: issues and policies. Paris: OECD; 2004.

Oldham GR, Cummings A. Employee creativity: personal and contextual factors at work. Academy of Management Journal 1996;39(3):607-34.

Perry-Smith JE, Shalley CE. The social side of creativity: a static and dynamic causal network perspective. Academy of Management Review 2003;28: 89-106.

Redmond MR, Mumford MD, Teach R. Putting creativity to work: effects of leader behavior on subordinate creativity. Organizational Behavior and Human Decision Processes 1993;55:120-51.

Salavou H, Lioukas S. Radical product innovations in SMEs: the dominance of entrepreneurial orientation. Creativity and Innovation Management 2003;12(2): 94-108.

Scott SG, Bruce RA. Determinants of innovative behavior: a path model of individual innovation in the workplace. Academy of Management Journal 1994;37(3):580-607.

Shalley CE, Gilson LL. What leaders need to know: a review of social and contextual factors that can foster or hinder creativity. Leadership Quarterly 2004;15(1):33-53.

Shalley CE, Zhou J, Oldham GR. The effects of personal and contextual characteristics on creativity: where should we go from here? Journal of Management 2004;30(6):933-58.

Shamir B, Zakay E, Breinin E, Popper M. Correlates of charismatic leader behavior in military units: subordinates' attitudes, unit characteristics, and superiors' appraisals of leader performance. Academy of Management Journal 1998;41:387-409.

Sheldon KM. Creativity and self-determination in personality. Creativity Research Journal 1995;8(1):25-36.

Shin SJ, Zhou J. Transformational leadership, conservation and creativity: evidence from Korea. Academy of Management Journal 2003;46(6): 703-14.

Siegel S, Kaemmerer W. Measuring the perceived support for innovation in organizations. Journal of Applied Psychology 1978;63:553-62.

Sosik JJ, Kahai SS, Avolio BJ. Transformational leadership and dimensions of creativity: motivating idea generation in computer-mediated groups. Creativity Research Journal 1998;11(2):11-121. 
Sosik JJ, Kahai SS, Avolio BJ. Leadership style, anonymity and creativity in group decision support systems. Journal of Creative Behavior 1999;33: 227-57.

Spreitzer GM. Psychological empowerment in the workplace: dimensions, measurement, and validation. Academy of Management Journal 1995;38(5): $1442-65$.

Taggar S. Individual creativity and group ability to utilize individual creative resources: a multilevel model. Academy of Management Journal 2002;45(2): 315-30.

Tierney P, Farmer SM, Graen GB. An examination of leadership and employee creativity: the relevance of traits and relationships. Personnel Psychology 1999;52:591-620.
Waldman DA, Atwater LE. The nature of effective leadership and championing processes at different levels in an R\&D hierarchy. The Journal of High Technology Management Research 1994;5(2):233-45.

Woodman RW, Sawyer JE, Griffin RW. Toward a theory of organizational creativity. Academy of Management Review 1993;18(2):293-321.

Zhou J. Feedback valence, feedback style, task autonomy, and achievement orientation: interactive effects on creative performance. Journal of Applied Psychology 1998;83(2):261-77.

Zhou J, George JM. When job dissatisfaction leads to creativity: encouraging the expression of voice. Academy of Management Journal 2001;44(4):682-96. 